\title{
Study of Antibiotic Resistance Pattern in Coagulase-negative Staphylococci strains Isolated from Clinical Specimens
}

\author{
Yousef Nami ${ }^{1}$, Mehdi Ghiami Rad ${ }^{2}$, Hamid Farah Bakhsh ${ }^{3}$, Nazila Imeni4, ${ }^{4}$ \\ ${ }^{1}$ Assistant Professor, Research Institute of Food Biotechnology, Iranian Agricultural Biotechnology Research Institute, \\ Agricultural Research and Extension Organization, Tabriz, Iran \\ 2 Assistant Professor, Department of Microbiology, Faculty of Sciences, Ahar Branch, Islamic Azad University, Ahar, Iran \\ ${ }^{3}$ Laboratory Expert, Ayatolah Hojjat Kouh-Kamri Hospital, Marand, Iran \\ ${ }^{4}$ MSc in Microbiology, Young Researchers and Elite Club, Marand Branch, Islamic Azad University, Marand, Iran
}

* Corresponding Author: Nazila Imeni, Young Researchers and Elite Club, Marand Branch, Islamic Azad University, Marand, Iran.E-mail: imeni.nazila94@gmail.com

Received: 16.05 .2018

Accepted: 14.08 .2018

How to Cite this Article:

Nami Y, Ghiami Rad M, Farah Bakhsh H, Imeni N. Study of Antibiotic Resistance Pattern in Coagulase-negative Staphylococci strains Isolated from Clinical Specimens. Avicenna $J$ Clin Med. 2018; 25(2): 85-91. DOI: $10.21859 /$ ajcm.25.2.85

\section{Abstract}

Background and Objective: Due to the emergence and development of antimicrobial resistance in coagulase-negative Staphylococci (CoNS), which is mainly a normal flora of the skin surface and mucous membrane of humans, and the limitation of therapeutic options, this study was aimed to investigate the antibiotic resistance pattern in CoNS strains isolated from clinical specimens.

Materials and Methods: In this cross-sectional descriptive study, a total of 44 isolates of coagulase-negative staphylococci were examined from clinical specimens of the patients using standard biochemical methods. Disc diffusion test was utilized to detect resistance to common antibiotics. Multiplex polymerase chain reaction (PCR) was employed to determine the frequency of resistance genes, namely mecA and vanA.

Results: The results of disc diffusion test showed that the isolates had the highest resistance rate to erythromycin as $88.64 \%$; while the lowest resistance rate to meropenem was observed $4.55 \%$. A molecular analysis indicated the presence of $18.18 \%$ of the mecA gene in the isolates; however no isolates containing vanA gene were observed.

Conclusion: Considering the frequency of mecA gene, results of antibiotic resistance pattern among coagulase-negative Staphylococci strains, and lack of any resistance observations to vancomycin by PCR, it is necessary to conduct more precise laboratory methods for the detection of antibiotic resistance to prevent resistance spread in this bacterium.

Keywords: Antibiotic Resistance, Coagulase-negative Staphylococci, Polymerase Chain Reaction 
dot: $10.21859 /$ ajcm. 25.2 .85

\title{
بررسى الكوى مقاومت آنتىبيوتيكى در ايزولههای/ستافيلوكوكوس كواتولاز منفى جداشده از نمونهاى بالينى
}

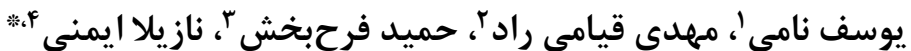

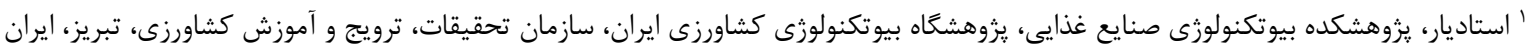

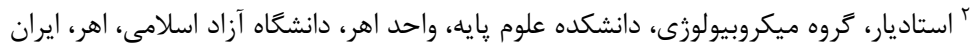

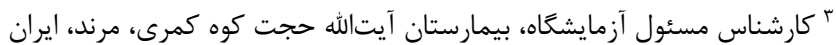

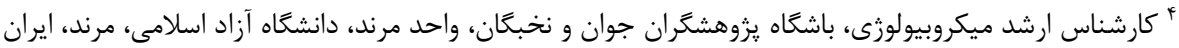
* *ويسنده مسئول: نازيلا ايمنى، باشكاه يزووهشَّر ان جوان و نخبكان، واحد مرند، دانشكاه آزاد اسلامى، مرند، ايران. ايميل: imeni.nazila94@gmail.com

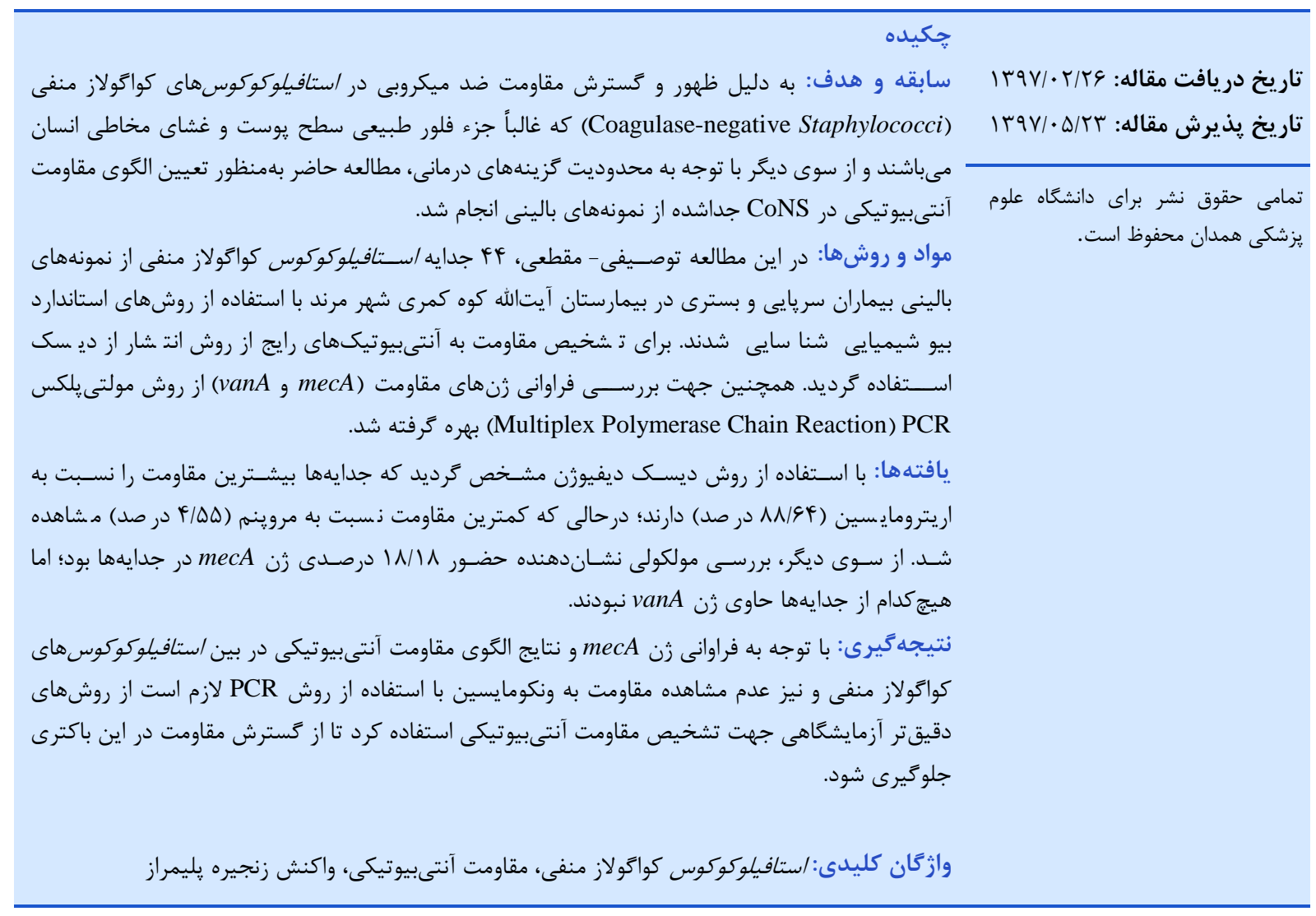

علاوهبراين، اين باكترىها شايعترين و سومين عامل اندوكارديت

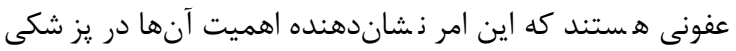

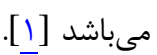

بسيارى از كونههاى CoNS بلهور معمول مقاوم به عوامل

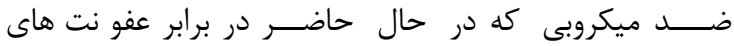
استافيلوكوكوس استفاده مىشوند، مىباشند. با اين وجود، تبادل

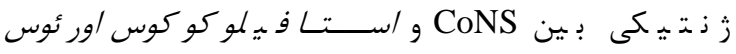
سبب تبديل /ستافيلوكوكوسهاى كوس ارنوس (Staphylococcus aureus)
استستـافيلوكوكوس هـاى كواكولاز منفى جزء فلور طبيعى

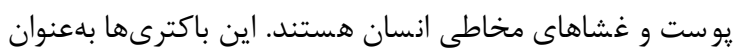

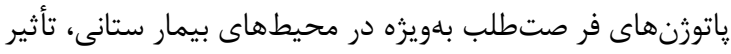

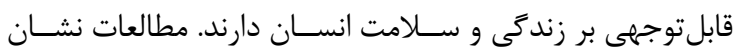

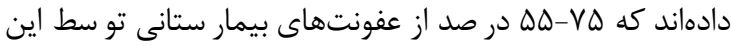

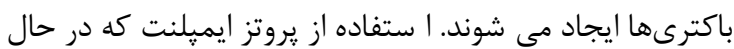

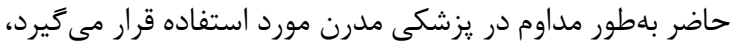

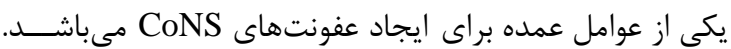


مطرح مىباشــند؛ مطالعه حاضـر بهمنظور تعيين الكوى مقاومت دارويى و رديابى ثنهاى كدكننده مقاومت آنتىبيوتيكى (mecA)

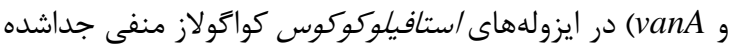
از نمونه واى بالينى انجام شد.

\section{مواد و روشى دما}

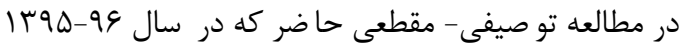

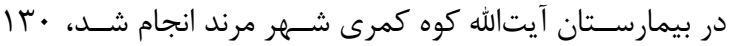

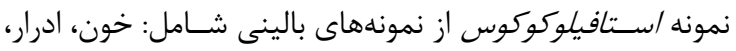
(Cerebro Spinal Fluid) CSF

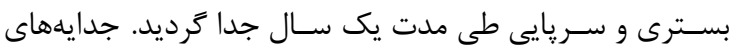

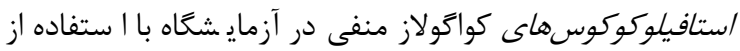

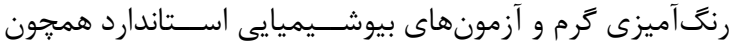

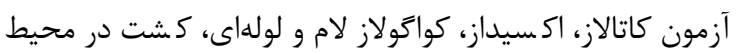

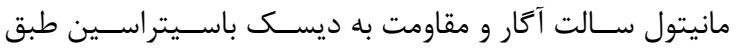

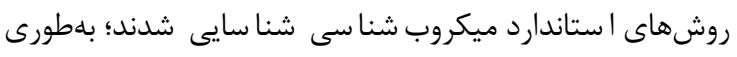

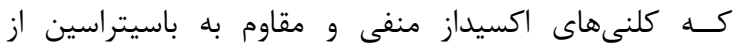
ميكروكو كوسها تفكيك گرد يد ند و بهعنوان كرفته شدند [^]ـ

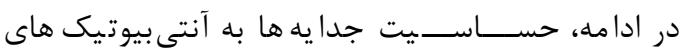

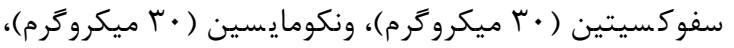

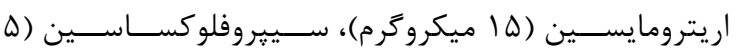

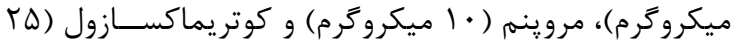

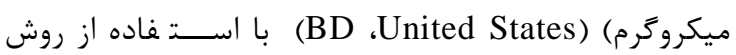

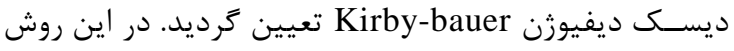

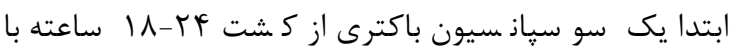
كدورتى معادل نيم مكفارلند تهيه گرديد و بر روى محيط ليط

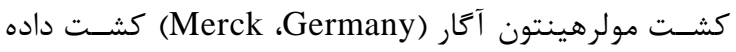

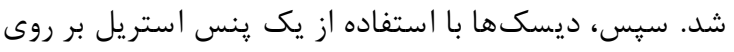

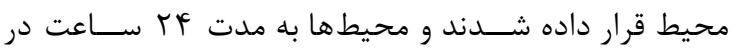

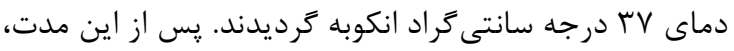

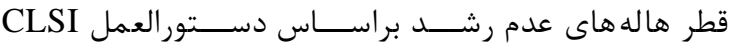
قرائت و (Clinical \& Laboratory Standards Institute)

$$
\text { ارزيابى شد [9].] }
$$

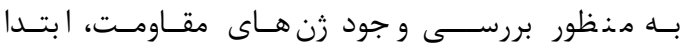

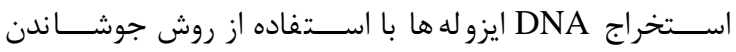
(Boiling)

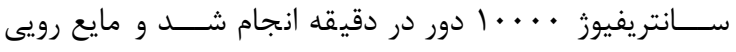

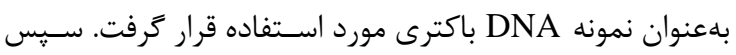

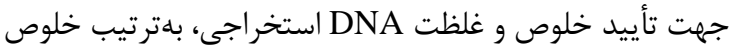

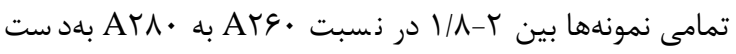

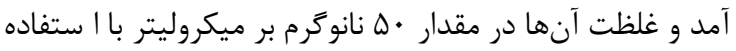

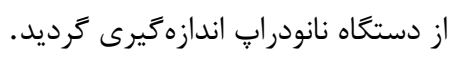

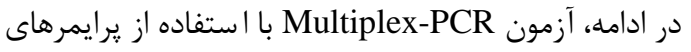

غيربيمارىزا به پاتوزن هاى مهاجم از جمله شـــيوع گَســرده

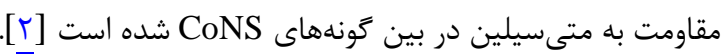

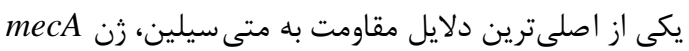

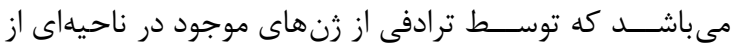

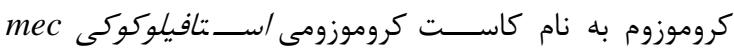
SCCmec: Staphylococcal Cassette Chromosome )

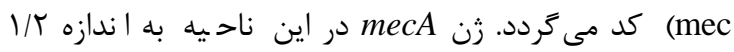

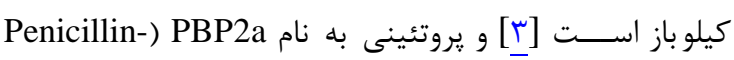
(Binding Protein2a به داروهاى بتالاكتام داشــه و مســئول مقاومت به متى ســـيلين

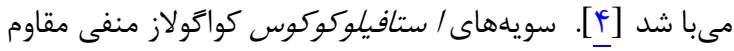

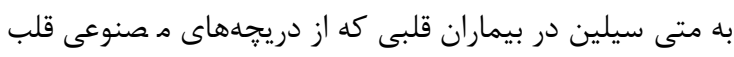

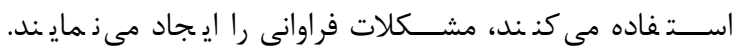

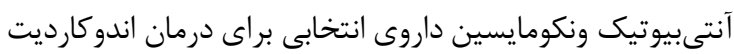

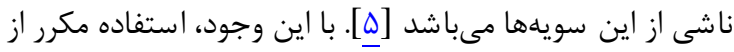
اين دارو موجب تبديل سـويههاى Methicillin-) MRCoNS (resistant Coagulase Negative Staphylococci Vancomycin Resistant Coagulase) VRCoNS Vancomycin ) VICoNS g (Negative Staphylococci (Intermediate Coagulase Negative Staphylococci

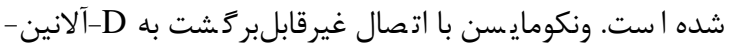

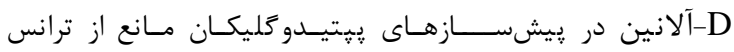

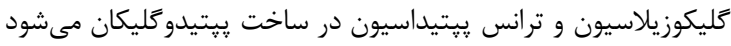

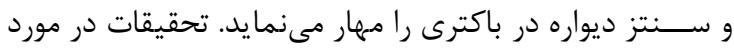

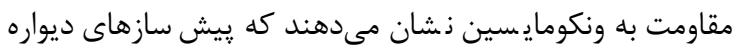

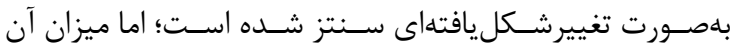

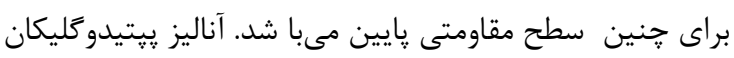

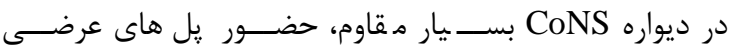

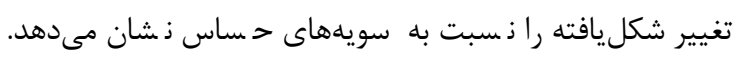
كزارش شده است كه اين يلهاى عرضى تغييرشكليافته، اتصال

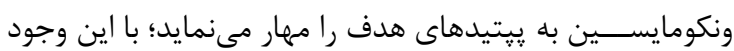

اين فرضيه ثابت نشده است [ع].

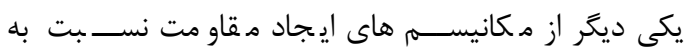

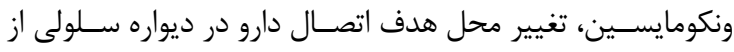

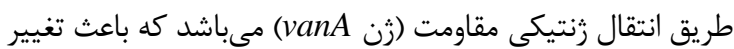

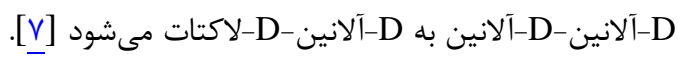

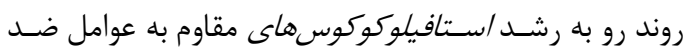
ميكروبى از جمله CoNS در سراسر جهان نيازمند سياستهاى روسي

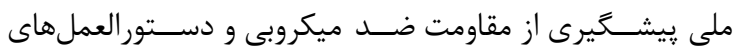

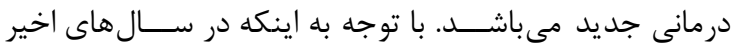

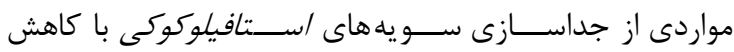

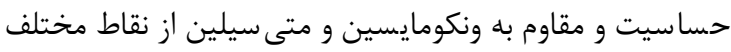

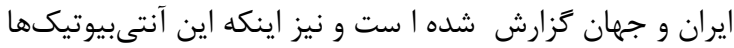

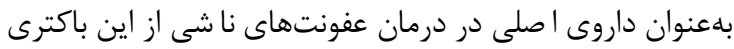


درجه سـلسـيوس به مدت • ץ ثانيه، اتصـال در دماى هل درجه

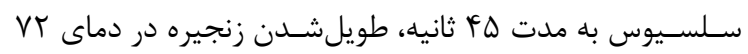
درجه سلسيوس به مدت ا دقيقه و طويل شدن نهايى در دماى

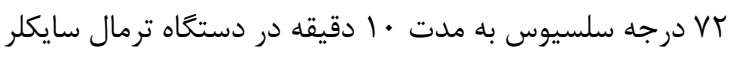
(BIORAD United States) محصول PCR در زل آتارز r درصد به مدت VD دقيقه در ولتاز
واكنش مربوط به زنهاى mecA و vanA انجام شــــ. واكنش در

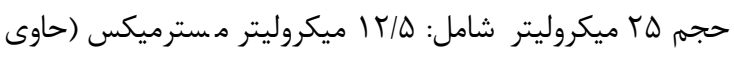
Taq

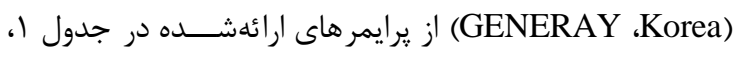
N/D ميكروليتر d/ d 1 ميكروليتر از DNA

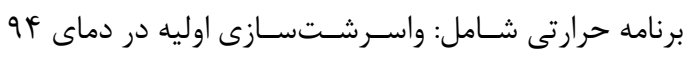

جدول ا: توالى يرايمرهاى مورد استفاده جهت رديابى زنهاى mecA و vanA در جدايهها

\begin{tabular}{|c|c|c|c|}
\hline منبع & يرايمر (' & اندازه قطعات تكثير شده & رُن \\
\hline 1. & $\begin{array}{l}\text { F: 3'-GTGAAGATATACCAAGTGATT-5' } \\
\text { R: 5'-ATGCGCTATAGATTGAAAGGAT-3' }\end{array}$ & IfV (bp) & mecA \\
\hline 11 & $\begin{array}{l}\text { F: 3'-CATGAATAGAATAAAAGTTGCAATA-5' } \\
\text { R: 5'-CCCCTTTAACGCTAATACGATCAA-3' }\end{array}$ & $1 \cdot r \cdot(b p)$ & $\operatorname{van} A$ \\
\hline
\end{tabular}

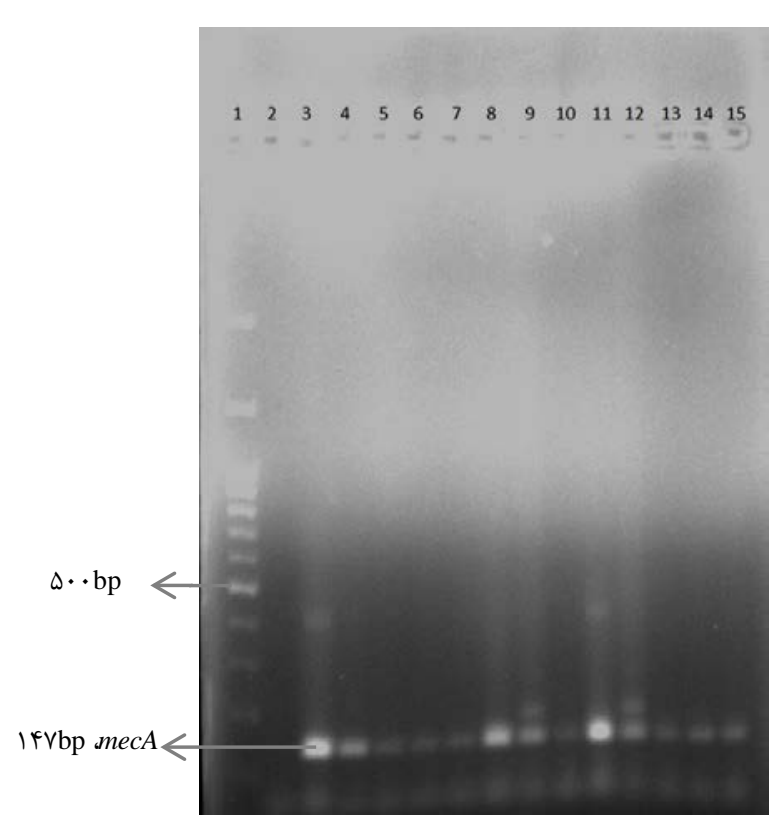

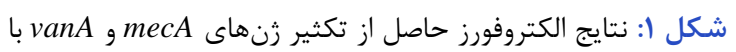

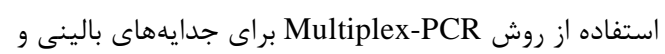

$$
\text { سويه هاى استاندارد }
$$

ستون 1 ماركر ․ جفت بازى؛ ستون ب سويه استاندارد

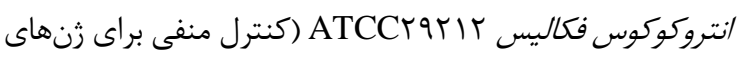
(vanA و mecA

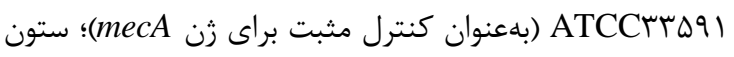

$$
\text { و و } 9 \text { جدايههاى مثبت مىباشند. }
$$

بحث

مطالعات جديد نشان مى دهند كه افزايش مقامت آنتىبيوتيكى

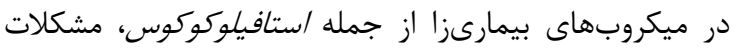

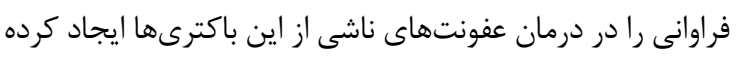

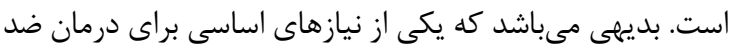

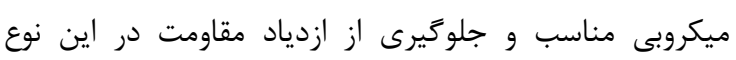

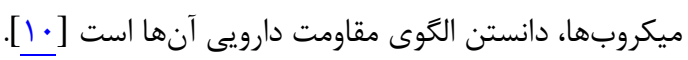

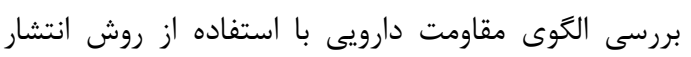

• و ولت صورت گرفت و يس از رنگ آميزى زل با سيف استين، در زير نور التراويوله بررسى كرديد.

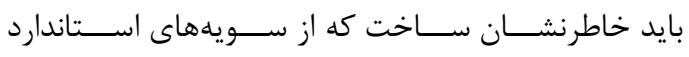

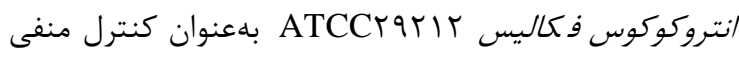

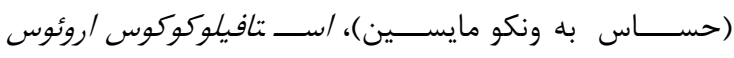

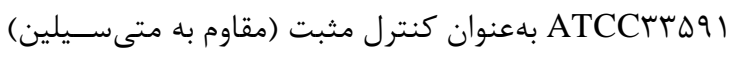

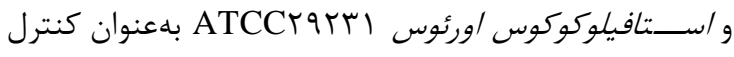

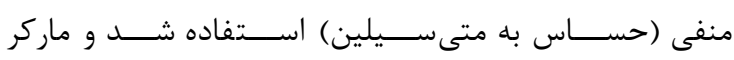

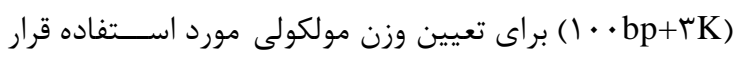

\section{يافته ها}

در اين مـطالعه در مجموع FF جدا يه /ســتافيلوكوكوس

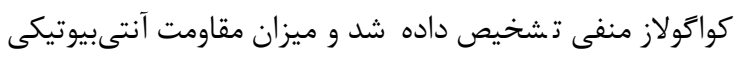

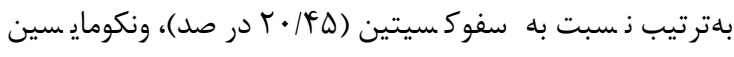

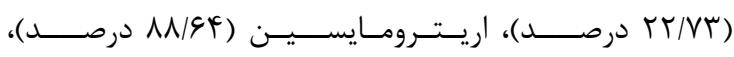

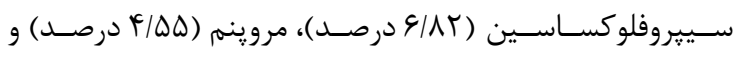

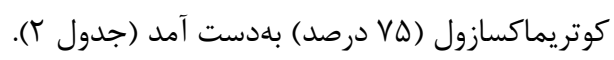

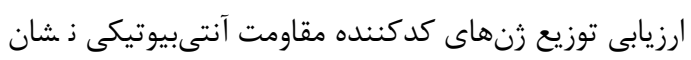

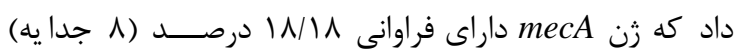

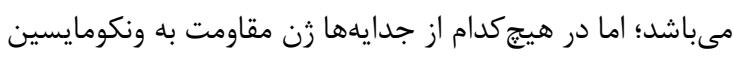

$$
\text { مشاهده نخرديد (شكل (1). }
$$

\begin{tabular}{|c|c|c|c|}
\hline مقاوم & نيمه حساس & حساس & آنتى بيوتيك \\
\hline$r \cdot / 4 \Delta$ & - & $\vee 9 / \Delta \Delta$ & سفوكسيتين \\
\hline TT/VT & - & $V V / T V$ & ونكومايسين \\
\hline $1 M / 94$ & - & 11/K4 & اريترومايسين \\
\hline GIAT & $F / Q F$ & $\Lambda \Lambda / G F$ & سييروفلوكساسين \\
\hline$f / \Delta \Delta$ & - & $9 \Delta / \uparrow \Delta$ & مروينهم \\
\hline VQ & - & $r \Delta$ & كو تريماكسازول \\
\hline
\end{tabular}

جدول ז: الكَوى حساسيت آنتىبيوتيكى ايزولههاى CoNS در مطالعه حاضر (درصد) 
انتقال زن مقاومت به ديكر سويههاى /ستافيلوكوكى كردد [IV]؛

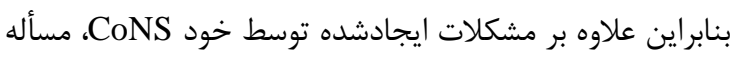

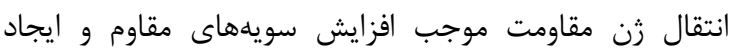

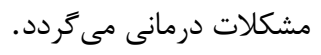

در مطالعه حاضر فراوانى زن mecA در جدائهاي

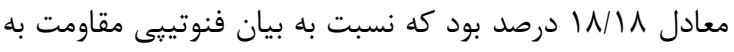

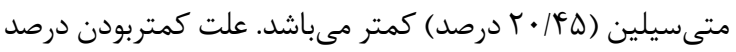

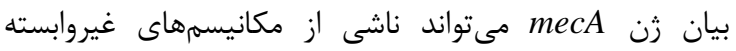

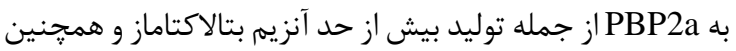

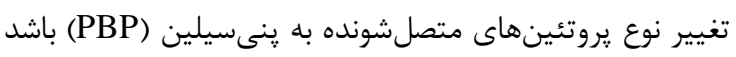

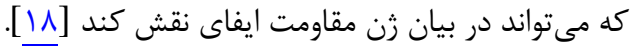

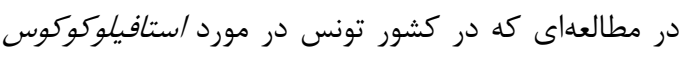

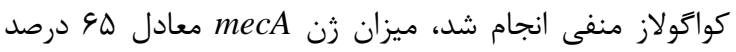

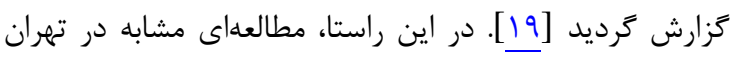

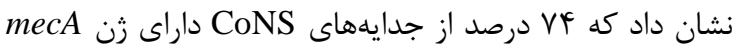

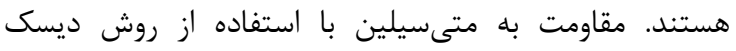

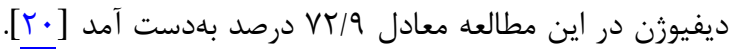

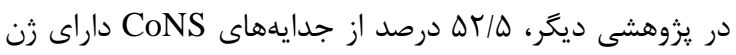

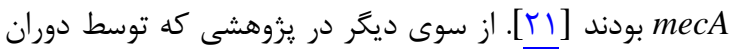

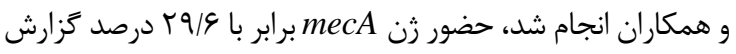

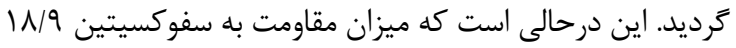

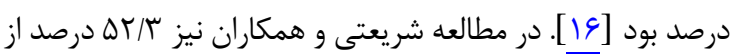

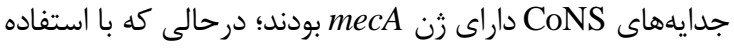

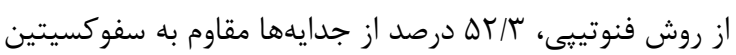

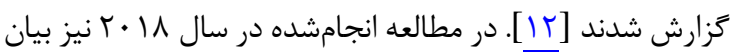

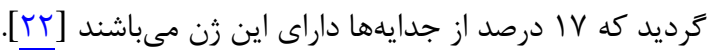

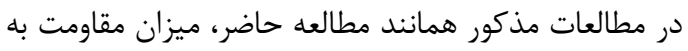

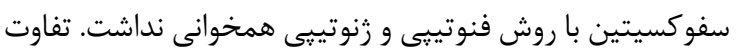

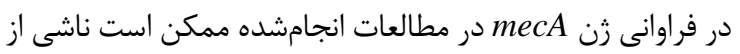

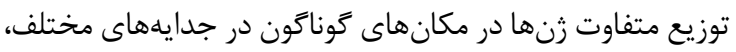

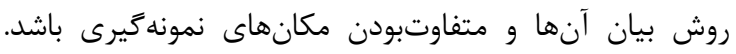

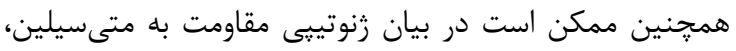

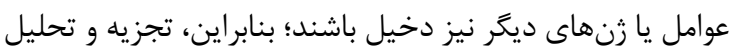

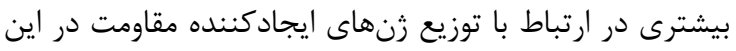
باكترى ها مورد نياز است. در نقاط مختلف جهان مطالعاتى در مورد بِيدايش سويههاي

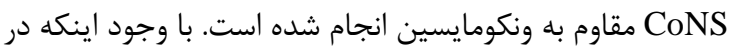

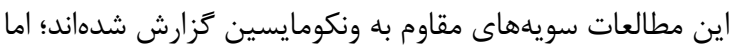

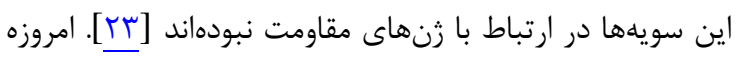

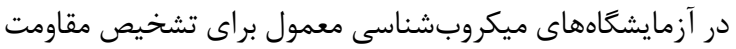

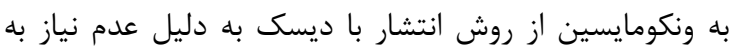

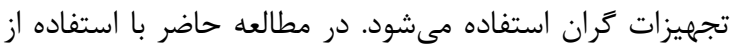

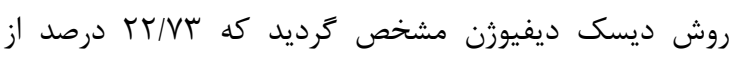
جدايهها نسبت به ونكومايسين مقاوم هستند؛ اما مشكل موجود درد دردي
ديسك در مطالعه حاضر نشان داد كه مروينهم و سييروفلوكساسين

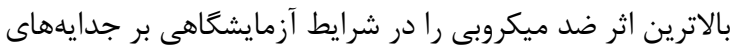

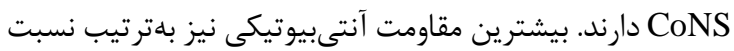

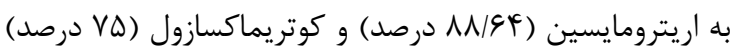

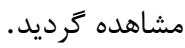
در مطالعات ديكر از جمله مطالعه اسكويى و همكاران،

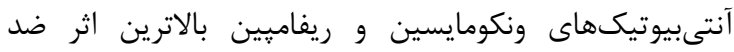

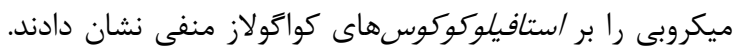

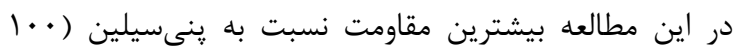

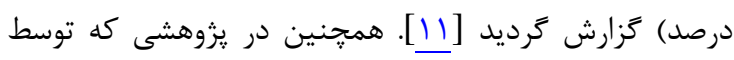

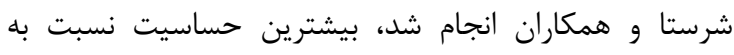

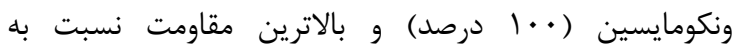

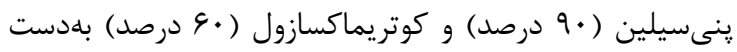

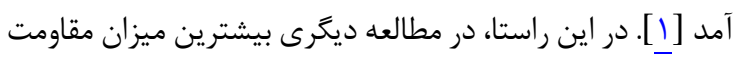

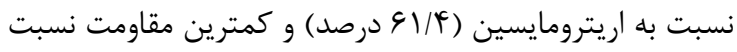

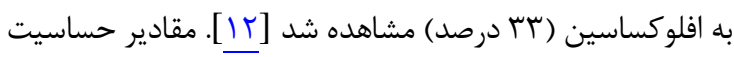

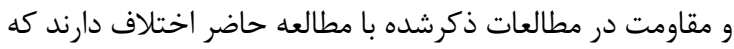

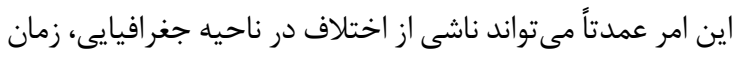

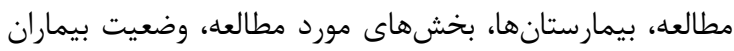
(بسترى و سريايى) و نوع عفونت باشد.

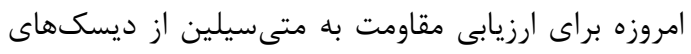

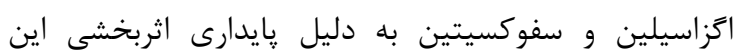

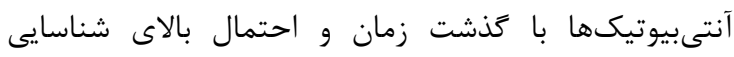

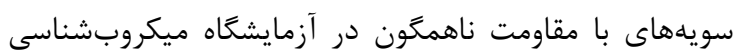

استفاده مىشود [بائ.

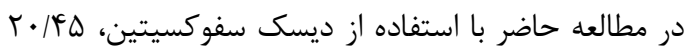

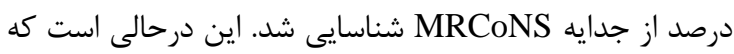

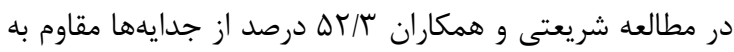

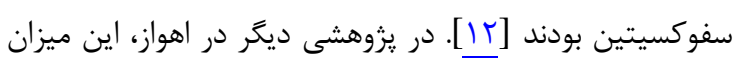

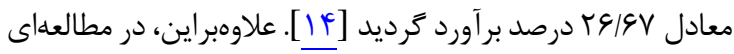

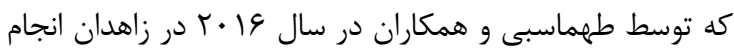

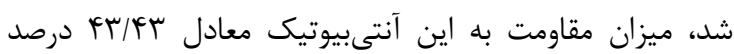

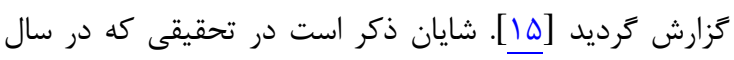

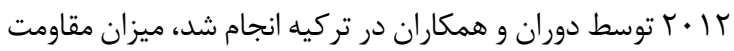

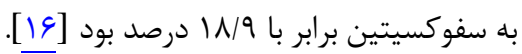
دليل تفاوت شيوع MRCoNS در مطالعه حاضر ممكن

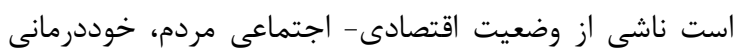

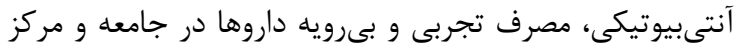

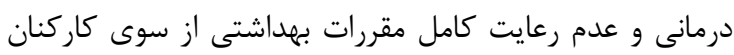

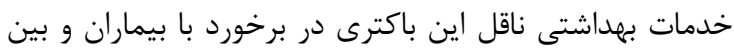

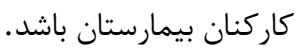

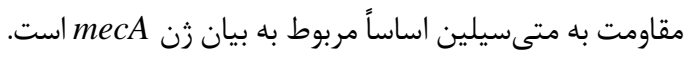
اين زن بر روى كاست كروموزومى استافيلوكوكى (SCCmec)

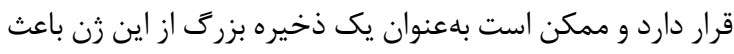




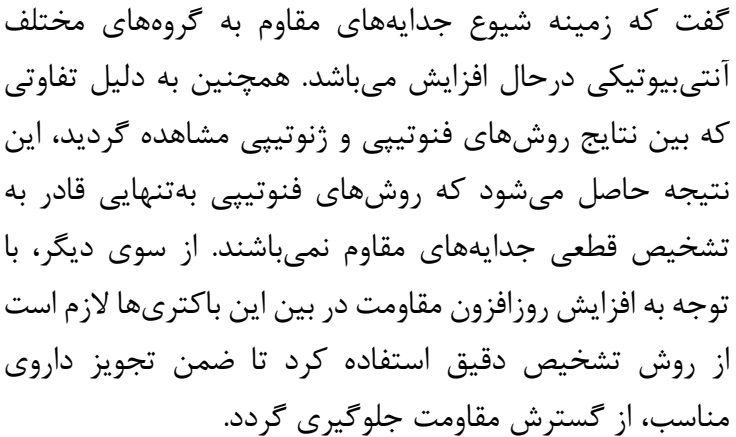

\section{تشكر و قلروراذى}

مقاله حاضر بركرفته از يايان نامه مصوب مؤسسه آموزش عالى

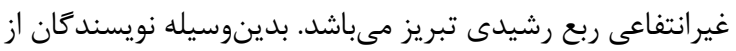
زحمات كاركنان محترم بخش ميكروبشناسى رئ بيمارستان آيتالله

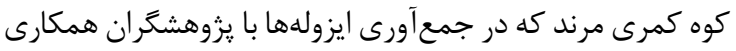

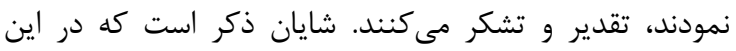
مطالعه هيجزَّنه تعارض منافعى بين نويسندًان و نتايج مطالعه

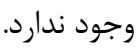

\section{REFERENCES}

1. Shrestha LB, Bhattarai NR, Khanal B. Comparative evaluation of methods for the detection of biofilm formation in coagulase-negative Staphylococci and correlation with antibiogram. Infect Drug Resist. 2018;11:607-13. PMID: 29731649 DOI: $10.2147 /$ IDR.S159764

2. Deyno S, Fekadu S, Seyfe S. Prevalence and antimicrobial resistance of coagulase negative Staphylococci clinical isolates from Ethiopia: a meta-analysis. BMC Microbiol. 2018;18(1):43. PMID: 29801462 DOI: 10.1186/s12866-0181188-6

3. Brooks GF, Carroll KC, Butel JS, Morse SA, Mietzner TA. Medical microbiology. 26 $6^{\text {th }}$ ed. New York: McGraw-Hill; 2013.

4. Zmantar T, Bekir K, Elgarsadi S, Hadad O, Bakhrouf A. Molecular investigation of antibiotic resistance genes in methicillin resistant Staphylococcus aureus isolated from nasal cavity in pediatric service. African J Microbiol Res. 2013;7(34):4414-21. DOI: 10.5897/AJMR2013.5778

5. Hiramatsu K. Vancomycin-resistant Staphylococcus aureus: a new model of antibiotic resistance. Lancet Infect Dis. 2001;1(3):147-55. PMID: 11871491 DOI: 10.1016/S14733099(01)00091-3

6. Diep BA, Carleton HA, Chang RF, Sensabaugh GF, Perdreau-Remington F. Roles of 34 virulence genes in the evolution of hospital- and community-associated strains of methicillin-resistant Staphylococcus aureus. J Infect Dis. 2006;193(11):1495-503. PMID: 16652276 DOI: 10.1086/ $\underline{503777}$

7. Gilani M, Usman J, Latif M, Munir T, Gill MM, Anjum R, et al. Methicillin resistant coagulase negative staphylococcus: from colonizer to a pathogen. Pak J Pharm Sci. 2016;29(4):1117-21. PMID: 27393446

8. Hamdan-Partida A, Sainz-Espunes T, Bustos-Martinez J. Characterization and persistence of Staphylococcus aureus strains isolated from the anterior nares and throats of healthy carriers in a Mexican community. $J$ Clin Microbiol. 2010;48(5):1701-5. PMID: 20335416 DOI: 10.1128/JCM. 01929-09

9. Ferraro MJ. Performance standards for antimicrobial susceptibility testing. $24^{\text {th }}$ ed. Wayne, PA: Clinical and Laboratory Standards Institute; 2014.

10. Beyene G, Tsegaye W. Bacterial uropathogens in urinary tract infection and antibiotic susceptibility pattern in Jimma University specialized hospital, southwest Ethiopia. Ethiop $J$
در روش انتشار ديسك ناشى از انتشار ضعيف آنتىبيوتيك ونكومايسين در بستر محيط كشت مىباشد. اين روش تنها براى شناسايى سويلهاى VRSA كه اندازه هاله آنها برابر با ع ميلىمتر مىباشد، كاربرد دارد [YY]]. بر اين اساس، در مطالعه حاضر بهمنظور شناسايى سويههاى مقاوم به ونكومايسين از روش

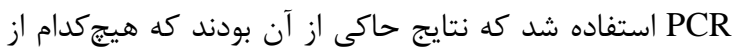
جدايهها داراى زن vanA نمى باشند.

در اين ارتباط در يزوهشى كه در هند انجام شد، هيج كدام از اه جدايه داراى زن vanA نبودند [هاب]. با اين وجود، استفاده

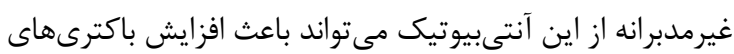
مقاوم به ونكومايسين شود؛ بنابراين، براى جلوخيرى از گسترش مقاومت در باكترى /ستافيلوكوكوس كواگولاز منفى مىبايست از تجويز بدون نسخه و استفاده غيرضرورى از آنتىبيوتيكهاى در دسترس خوددارى نمود.

نتيجه گيرى

Health Sci. 2011;21(2):141-6. PMID: 22434993

11. Oscoei Abdoli S, Ahangarzadeh Rezaei M, Ajang A, Abdinia B. Determination of antibiotic resistance pattern and minimum inhibitory concentration of vancomycin in Staphylococcus aureus and coagulase negative isolated from pediatric clinical samples in Tabriz. J Ardabil Univ Med Sci. 2013;13(1):25-34. [Persian]

12. Shariati L, Shojapour M, Validi M, Farrokhi E, Tabatabaiefar MA, Karimi A, et al. The investigation of prevalence of methicillin and vancomycin resistance in coagulase negative Staphylococci isolated from clinical samples of Shahrekord university hospitals, 2009. Iran South Med J. 2011; 14(3):165-72. [Persian]

13. Ahmadi SS, Nahaei MR, Amir MN. Sensitivity of staphylococcus aureus strains isolated from clinical specimens against vancomycin by using E-test in Tabriz. Med J Tabriz Univ Med Sci. 2002;30(2):17-23.

14. Jamshidian M. Methicillin resistance in Staphylicoccus strains isolated from clinical samples in Ahwaz. Med J Tabriz Univ Med Sci. 2001;35:29-33.

15. Tahmasebi H, Bokaeian M, Abadi J. Phenotypic and molecular study of beta-lactam resistance in coagolazenegative Staphylococci samples. Pars J Med Sci. 2016; 14(1):55-63. [Persian]

16. Duran N, Ozer B, Duran GG, Onlen Y, Demir C. Antibiotic resistance genes \& susceptibility patterns in Staphylococci. Indian J Med Res. 2012;135:389-96. PMID: 22561627

17. Rosenthal ME, Dever LL, Moucha CS, Chavda KD, Otto M, Kreiswirth BN. Molecular characterization of an early invasive Staphylococcus epidermidis prosthetic joint infection. Microb Drug Resist. 2011;17(3):345-50. PMID: 21510745 DOI: $10.1089 / \mathrm{mdr} .2010 .0157$

18. Choi SM, Kim SH, Kim HJ, Lee DG, Choi JH, Yoo JH, et al. Multiplex PCR for the detection of genes encoding aminoglycoside modifying enzymes and methicillin resistance among Staphylococcus species. J Korean Med Sci. 2003;18(5):631-6. PMID: 14555812 DOI: $10.3346 / \mathrm{jkms}$. 2003.18.5.631

19. Bouchami O, Achour W, Hassen AB. Species distribution and antibiotic sensitivity pattern of coagulase-negative Staphylococci other than Staphylococcus epidermidis isolated from various clinical specimens. Afr J Microbiol Res. 2011;5(11):1298-305. DOI: 5897/AJMR11.112

20. Mirsalehian A, JabalAmeli F, Kazemi B, Alizadeh SA. 
Comparison of disk diffusion method with polymerase chain reaction for detecting methicillin resistance in clinical isolates of Staphylococci. Tehran Univ Med J. 2003; 61(6):420-5. [Persian]

21. Nafisi M, Kalhor H, Zamanzad B, Karimi A, Farokhi A, Validi M. Comparison of agar screen and duplex-PCR in determination of methicillin resistant Staphylococcus aureus (MRSA) strains isolated from nose of personnel in Hajar hospital of Shahre-Kord. Arak Univ Med Sci J. 2008; 11(2):94-101. [Persian]

22. Nobrega DB, Naushad S, Naqvi SA, Condas LA, Saini V, Kastelic JP, et al. Prevalence and genetic basis of antimicrobial resistance in non-aureus Staphylococci isolated from Canadian dairy herds. Front Microbiol. 2018;9:256.
PMID: 29503642 DOI: 10.3389/fmicb.2018.00256

23. Courvalin P. Vancomycin resistance in gram-positive cocci. Clin Infect Dis. 2006;42:S25-34. PMID: 16323116 DOI: 10.1086/491711

24. Jones RN. Microbiological features of vancomycin in the 21st century: minimum inhibitory concentration creep, bactericidal/static activity, and applied breakpoints to predict clinical outcomes or detect re-sistant strains. Clin Infect Dis. 2006;42(1):S13-24. PMID: 16323115 DOI: 10.1086/491710

25. Tiwari HK, Sen MR. Emergence of vancomycin resistant Staphylococcus aureus (VRSA) from a tertiary care hospital from northern part of India. BMC Infect Dis. 2006;6:156. PMID: 17067393 DOI: 10.1186/1471-2334-6-156 